\title{
Recycling of poly lactic acid into lactic acid with high temperature and high pressure water
}

\author{
M. Faisal ${ }^{1,2}$, T. Saeki ${ }^{1}$, H. Tsuji ${ }^{1}$, H. Daimon ${ }^{1} \&$ K. Fujie ${ }^{1}$ \\ ${ }^{1}$ Department of Ecological Engineering, \\ Toyohashi University of Technology, Japan \\ ${ }^{2}$ Department of Chemical Engineering, Syiah Kuala University, \\ $N A D$, Indonesia
}

\begin{abstract}
The converting of poly L-lactic acid into its monomer (lactic acid) was performed using high temperature and high pressure water at the temperature range of $250-350^{\circ} \mathrm{C}$ and for a period of 30 minutes. The results show that temperature and reaction time affected the recycling efficiency and optical selectivity. Under the tested conditions, the highest amount of lactic acid (yield of $90.7-92.5 \%$ ) was obtained at temperature of $250^{\circ} \mathrm{C}$ and reaction time of $10-20$ min. The remains were an un-harmful byproduct. A study on the effect of temperature on the optical purity of lactic acid product demonstrated L-lactic acid was predominant at a low range temperature of $250-260^{\circ} \mathrm{C}$. At higher temperature, racemic mixture was observed. Based on our experimental results, the method was found to be simple and promising for recycling of poly lactic acid into its monomer, lactic acid.
\end{abstract}

\section{Introduction}

The replacement of highly biodegradation-resistant and petroleum-based plastics with biodegradable ones, such as poly lactic acid (PLA), is of interest to researchers. PLA can be synthesized from renewable resources (e.g. corn, wheat, potato or sugar beat) by fermentation. Due to its biocompatibility and biodegradability, PLA has widespread potential use in medicine, agriculture, and packaging applications $[1,2]$. Recently, Cargill Dow LLC has started to operate the PLA plant producing of 140,000 t/year in November 2001. They are planning to increase annual output up to $450,000 \mathrm{t}$ in 2010 [3]. 
However, biodegradable plastics also pose some adverse environmental risk such as pollution in waterways due to high BOD concentration resulting from the breakdown of starch-based biodegradable plastics. PLA releases carbon dioxide and methane during its biological breakdown phase, migration of plastic degradation by products (i.e., contaminant additives and modifiers) and slow degradation rate [4] where its microbial degradation is limited to a few species of microorganism, such as Amycolatopsis and Streptomyces strain [5,6]. In fact, the annual production of PLA increases markedly [3]. Any large-scale consumption of PLA products will bring the associated problem of an excess of PLA waste, which will difficult to treat by biodegradation either in composting plants or in the natural environment [7].

Consequently, PLA should be recycled into its monomer, lactic acid, instead of disposing it, and afterward can reproduce the same polymer. The recycling is supposed to lead the simultaneous solution of energy, resources, $\mathrm{CO}_{2}$ and waste problem. Moreover, minimizing resource consumption as well as efficient utilization of renewable resources should be established for the sustainable system. Recycling of PLA oligomers to produce cyclic dimer (L-lactide) in the presence of catalyst has been reported [8]. However, this method is requiring the catalyst. Moreover, the yield of L-lactide was low at a short reaction time. A high temperature and high pressure (HTHP) water treatment, an environmentally friendly recycling process which only uses water is effective for recovery of lactic acid from PLA without addition of any catalysts.

In recent years, the use of HTHP water treatment process for thermal decomposition [9-11], organic synthesis [12,13] and recovery of useful materials from various organic wastes [14-18] has attracted the interest of many researchers. This technique was also applied to chemical recycling processes such as hydrolysis of polyethylene terephthalate (PET) into ethylene glycol and terephthalic acid [19]. Park et al. [20] showed the ability of supercritical and near-critical water to break down the styrene-butadiene rubber (SBR) into a range of lower molecular weight organic compounds for potential recovery. Thus, water under HTHP conditions provides excellent properties (i.e. high ion product, low solvent polarity, high solubility for oil, etc.) for hydrolysis and offer opportunities to adjust the reaction environment to optimal conditions for the chemical transformation of interest [21].

In this work, our effort is to present a way to prepare lactic acid from poly L-lactic acid (PLLA) under a promising technique. Optimum condition of recovery, effect of high temperature on DL type of lactic acid will be discussed. The result is significant for development of recycling technology and biomass efficiency.

\section{Experimental}

All experiments were performed using SUS 316 batch reactor $(8.2 \mathrm{ml}$ volume, $12.7 \mathrm{~mm}$ OD, $10.2 \mathrm{~mm} \mathrm{ID}$, and $100 \mathrm{~mm}$ length). The reaction conditions were over a temperature range of 250 to $350^{\circ} \mathrm{C}$ at the corresponding saturated vapor pressures and time ranging from 1 to 30 minutes. During a typical run, about 
0.24 g PLLA (LACTY 5000, Shimadzu Corp., weight average molecular weight $(\mathrm{Mw})=4.4 \times 10^{5}, \mathrm{Mw} /$ number average molecular weight $(\mathrm{Mn})=2.1$, initial fraction of L-lactic acid $=95 \%$ ) and $4.8 \mathrm{~g}$ of distilled water (weight ratio of 1:20) were charged into the reactor. The reactor was then sealed, and then the air inside was replaced by Argon gas. Subsequently, the reactor was immersed into the preheated molten salt bath (TSC-B600, Taiatsu Techno) containing a mixture of potassium nitrate and sodium nitrate set at the desired temperature. After the desired reaction time had elapsed, the reactor was plunged into a water bath to bring them quickly to room temperature, thus, effectively ceasing any occurring reactions. The reaction products were analyzed using an organic acid analyzer (LC-10A, Shimadzu Corp.) with an ion-exclusion column (Shim-Pack SCR102H, Shimadzu Corp.) and electroconductivity detector (CDD-6A, Shimadzu Corp.). The optical isomer of lactic acid produced was also analyzed using these conditions: analytical column; Sumichiral OA-5000 (5 $\mu \mathrm{m}$ particle size, $4.6 \mathrm{~mm}$ i.d. x $150 \mathrm{~mm}$ long, Sumika Chemical Analysis Service Ltd. Japan), column temperature; $30^{\circ} \mathrm{C}$, mobile phase; $1 \mathrm{mM}$ copper (II) sulfate in water, flow rate; $1 \mathrm{~mL} /$ minutes, injection volume $20 \mu \mathrm{L}$. The total organic carbon (TOC) was analyzed using TOC analyzer (TOC-VE, Shimadzu Corp.).

\section{Results and discussion}

\subsection{Temperature and time dependence on lactic acid production}

The effect of temperatures on thermal recycling of PLLA into lactic acid and other organic acids (i.e. pyrubic, succinic, propionic, acetic and formic, acids) at $10 \mathrm{~min}$ of reaction time is demonstrated in Figure 1. The products were mostly lactic acid with small amount of by products. As can be seen from the Figure, the amount of lactic acid was found to increased with the increased of reaction temperature up to $250^{\circ} \mathrm{C}$ then decreased as temperature rises $350^{\circ} \mathrm{C}$. It was observed that in the low temperature range of $200-230^{\circ} \mathrm{C}$ and short reaction time (5-10 $\mathrm{min}$ ), the thermal depolymerization of PLLA results only the reduction of molecular weight, suggesting thermal energy was insufficient to produce lactic acid. At these conditions, acetic and formic acid which are the major intermediate products prior to complete degradation to volatile carbon and water [22] were not observed, suggesting that the depolymerization occurs without the formation of volatile product. Our observation showed that at a low temperature ranging from $240-250^{\circ} \mathrm{C}$ succinic acid was observed, while at higher temperatures, propionic and acetic acid were observed.

Figure 2 shows the effect of reaction times on thermal recycling of PLLA at $250^{\circ} \mathrm{C}$. Results demonstrated that from 8-30 min of reaction time, formation of lactic acid do not change markedly, indicating that the depolymerization reaction occurs relatively slow at these conditions. It was observed also that the formation of other low molecular weight organic compounds decreased as time progresses. Based on Figures 1 and 2, the results suggest that both temperature and time affect the amount of lactic acid obtained. 


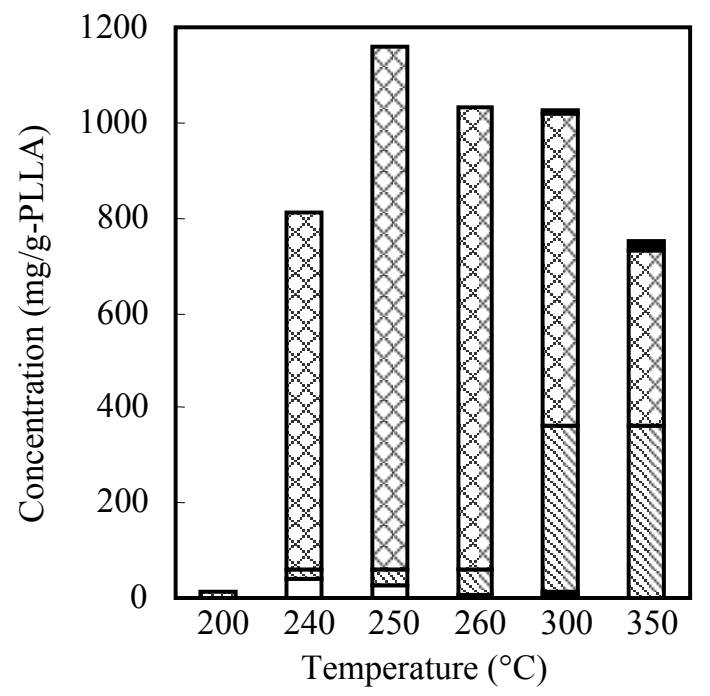

Figure 1: Effect of temperature on thermal recycling of PLLA at $10 \mathrm{~min}$ of reaction time.

- Propionic, Acetic, Formic acid, \ L-Lactic acid

D D-Lactic acid, $\square$ Succinic, Pyrubic acid

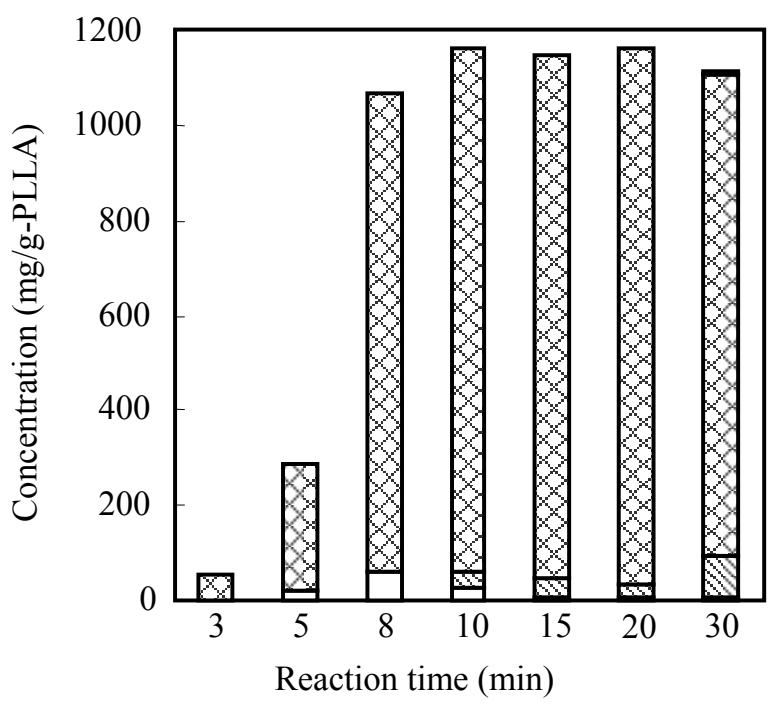

Figure 2: Effect of reaction time on thermal recycling of PLLA at $250^{\circ} \mathrm{C}$ of poly lactic acid at $250^{\circ} \mathrm{C}$. 
The recycling efficiency, strongly depend upon the reaction conditions. Table 1 summarizes the results of the recycling efficiency of PLLA at various conditions. As can be seen, at $250^{\circ} \mathrm{C}$ and $20 \mathrm{~min}$ of reaction time, $92.5 \%$ of PLLA was converted into lactic acid. Presumably, the ion product of water is good enough for lactic acid recovery under this temperature. The ion product of water goes through a maximum (about $10^{-11}(\mathrm{~mol} / \mathrm{L})^{2}$ ) at about $250^{\circ} \mathrm{C}$ under a pressure of $4 \mathrm{MPa}$. Large amount of dissociated ions and high dielectric constant might also promote depolymerization process. Then, the yield of lactic acid decreased at $30 \mathrm{~min}$. At a higher temperature of $350^{\circ} \mathrm{C}$, the degradation rate of PLLA was fast and small amount of propionic and acetic acid were observed. This result suggests that, further decomposition of acetic acid might have occurred producing carbon monoxide and eventually carbon dioxide.

To obtain additional information concerning the recycling of PLLA, further experiment on the effect of ratio water to sample (PLLA) were also done with the ratio of 10:1 (water:PLLA). Results show that at 10 min of reaction time the yield of lactic acid was found lower than that of the ratio of 20:1. Small amount of un-reacted material was observed. Probably, at this condition the amount of water produce insufficient of $\mathrm{OH}$ radical concentration for degradation of PLLA.

The conversion yield of PLLA into lactic acid could be improved by manipulating some conditions. Reaction time, temperature and pressure have been found as key parameters on the recycling of PLLA. The addition of selected catalyst might also improve the yield of lactic acid. The using of agitated reactor will affect the mass transfer inside the reactor which is might influence the yield of lactic acid. Kao et al. [23] reported that the rate of PET hydrolysis increased with the agitation speed and approach a constant value when the agitation speed was larger than $400 \mathrm{rpm}$. In addition, our preliminary experiment on the effect of reactor material on the reaction also showed that reaction rate in SUS 316 material was slightly higher than that of Hastelloy C-22 and Inconel 625.

Table 1: Recycling efficiency of PLLA into lactic acid at various conditions.

\begin{tabular}{c|lcccc}
$\begin{array}{c}\text { Reaction } \\
\text { time } \\
\text { (min) }\end{array}$ & $240^{\circ} \mathrm{C}$ & $250^{\circ} \mathrm{C}$ & $260^{\circ} \mathrm{C}$ & $300^{\circ} \mathrm{C}$ & $350^{\circ} \mathrm{C}$ \\
\hline 5 & 11.9 & 21.6 & 53.9 & 67.4 & 55.5 \\
8 & 35.2 & 80.1 & 70.8 & 71.9 & 46.7 \\
10 & 61.7 & 90.7 & 84.8 & 83.8 & 42.0 \\
15 & 85.5 & 91.1 & 89.2 & 83.0 & 30.1 \\
20 & - & 92.5 & 91.5 & 82.5 & 22.0 \\
30 & - & 88.4 & 80.1 & 79.9 & 12.7
\end{tabular}

\subsection{Effect of temperature and reaction time on DL-types of lactic acid}

Since L-type of lactic acid is a significant important compare to D-type or racemic mixture, the measurement of the effect of HTHP water process on DL- 
types of lactic acid is highly useful. Figure 3 demonstrates the course of the selectivity to L-lactic acid at the conditions employed in this work. The L fraction of lactic acid was calculated based upon the initial L-fraction in the sample, ca.95\%. As can be seen, the selectivity value for L-lactic acid at short reaction time and temperature range of $250-260^{\circ} \mathrm{C}$ were found at around 1 indicating the insignificance change in optical purity occurred during recycling process. Moreover, the selectivity of L-lactic acid remained unchanged for a period of 30 minutes at the temperature of $250^{\circ} \mathrm{C}$. These findings suggest that the degradation of PLLA at these conditions results in only L-lactic acid and watersoluble oligomers. As expected, at a higher temperature, the selectivity decreased gradually with reaction time. For instance, at $300^{\circ} \mathrm{C}$ and 20 minutes of reaction time, the selectivity was reduced to 0.55 indicating the racemization occurred resulting in the partial loss of optical activity. In other words $45 \%$ of Lenantiomer was converted to D-lactic acid. This result reflects that L-lactic acid changed into D-lactic acid at high temperature through the contribution of radical-homolysis and enolization pathways as suggested by Tsuji et al. [24]. These findings reveal that the temperatures ranging from $250-260^{\circ} \mathrm{C}$ are most favorable for high yield of L-lactic acid.

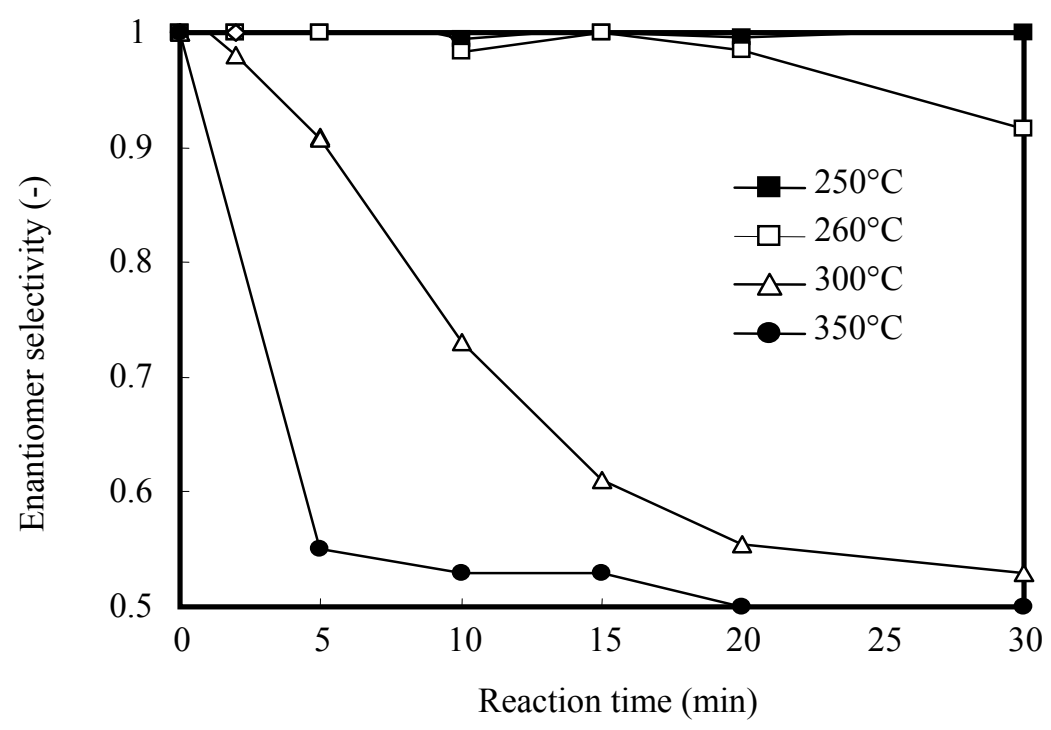

Figure 3: Course of enantiomer selectivity to L-lactic acid at various temperatures.

\subsection{Carbon balance}

The PLLA degradation process was also investigated by TOC measurements. Figure 4 demonstrates the effects of time and temperature on the course of TOC 
reduction. The value 1 means the theoretical TOC value when all of the PLLA chains are degraded completely to produce lactic acid, water-soluble oligomers and other organic acids. A significant increase of the TOC with increasing reaction temperature and time was found as expected. As can be seen in Figure 4, at $8-15$ minutes of reaction times and temperatures of $250-300^{\circ} \mathrm{C}$, the amount of TOC achieved a maximum and reached a theoretical value suggested that all of the PLLA chains were degraded into its monomer, water-soluble oligomers and other organic acids. The TOC value then remained unchanged even when the reaction was continued for 30 minutes, which was in contrast with the lactic acid formation (excluding the result at $250^{\circ} \mathrm{C}$ ). These occurred presumably due to the formation of low molecular carboxylic acids (from lactic acid) such as acetic acid. As expected, at higher temperature of $350^{\circ} \mathrm{C}$, TOC decreased significantly with reaction time exceeding 5 minutes. This suggests that volatile carbon such as $\mathrm{CO}_{2}, \mathrm{CO}$ and $\mathrm{CH}_{4}$ were formed by thermal decomposition of lactic acids through decarboxylation and the dehydration route of decomposed compounds [11].

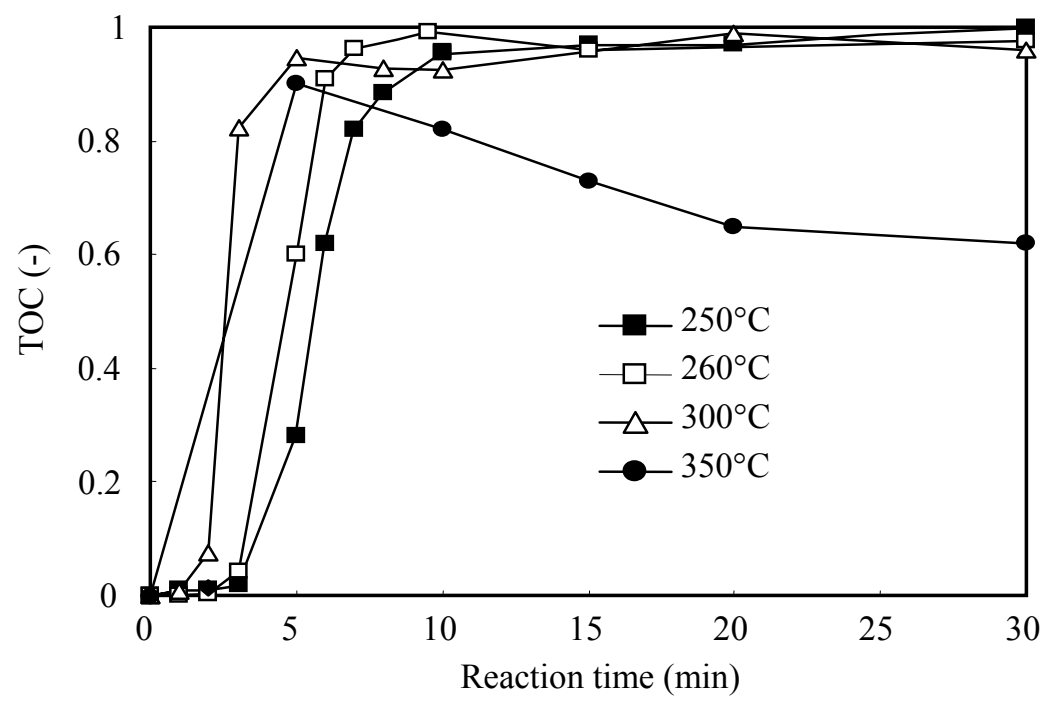

Figure 4: Course of TOC reduction at various conditions.

\section{Conclusion}

Recycling of PLA was investigated in a pressurized batch reactor at subcritical conditions. The recycling efficiency was strongly dependence upon the operating conditions of temperature, reaction time and ratio water to sample. The monomers recovered mainly consist of lactic acid. Our observation shows that the recycling to lactic acid appears predominant at lower temperatures, while at the higher temperatures was favorable to thermal degradation into other low 
molecular weight carboxylic acids. Our observation suggests that HTHP water process has been found to affect the optical isomer of lactic acid. At low temperatures, it was observed that monomer recovered mainly consist of L-lactic acid.

\section{Acknowledgement}

The authors are grateful to The 21st Century COE Program at the Toyohashi University of Technology (Ecological Engineering for Homeostatic Human Activities) for financial support of this research.

\section{References}

[1] Datta, R. and S.P Tsai; "Lactic acid production and potential uses: a technology and economic assessment”, Am. Chem. Soc., Chp 12, pp. $225-$ 235, 1997

[2] Chiellini, E. and R. Solaro; "Biodegradable polymer materials", Adv. Mater., 8, pp. 303-313, 1996

[3] Verespej, MA.; "Winning technologies: polylactic polymer", Industry Week, Dec 11, 2000

[4] Brown, D.; "Plastics packaging of food products: the environmental dimension", Trends Food Sci. Technol., 4, pp. 294-300,1993

[5] Pranamuda, H. and Y. Tokiwa; "Degradation of poly(L-lactide) by strains belonging to genus Amycolatopsis“, Biotechnol. Lett., 21, pp. 901-905, 1999

[6] Pranamuda, H., Y. Tokiwa, and H. Tanaka; "Polylactide degradation by an Amycolatopsis sp.”, Appl. Environ. Microbiol., 63, pp. 1637-1640, 1997

[7] Fan, Y., H. Nishida, T. Mori, Y. Shirai and T. Endo; "Thermal degradation of poly (L-lactide): Effect of alkali earth metal oxides for selective L,L-lactide formation", Polymer, 45, pp.1197-1205, 2004

[8] Noda, M. and H. Okuyama; "Thermal catalytic depolymerization of poly (L-lactic acid) oligomer into LL-lactide: effects of $\mathrm{Al}, \mathrm{Ti}, \mathrm{Zn}$ and $\mathrm{Zr}$ compounds as catalyst", Chem. Pharm. Bull., 47, pp. 467-471, 1999

[9] Goto, M., T. Nada, S. Kawajari, A. Kodama and T. Hirose; "Decomposition of municipal sludge by supercritical water oxidation", J. Chem. Eng. Japan, 30, pp. 813-818, 1997

[10] Goto, M., T. Nada, A. Ogata, A, Kodama and T. Hirose; "Supercritical water oxidation for the destruction of municipal excess sludge and alcohol distillery wastewater of molasses", J. Supercrit. Fluids, 13, pp. 277-182, 1998

[11] Li, L., J.R. Portela, D. Vallejo and E.F. Gloyna; "Oxidation and hydrolysis of lactic acid in near - critical water", Ind. Eng. Chem. Res., 38, pp. 2599-2606, 1999

[12] Savage, P.E.; "Organic chemical reactions in supercritical water", Chem. Rev., 99, pp. 603-621, 1999 
[13] Holliday, R.L., B.Y.M. Jong and J.W. Kolis; "Organic synthesis in subcritical water oxidation of alkyl aromatic”, J. Supercrit. Fluids, 12, pp. 255-260, 1998

[14] Kang, K., A.T. Quitain, H. Daimon, R. Noda, N. Goto, H. Hu and K. Fujie; "Optimization of amino acids production from fish entrails by hydrolysis in sub-and supercritical water”, Can. J. Chem. Eng., 79, pp. 6570,2001

[15] Shanableh, A.; "Production of organic matter from sludge using hydrothermal treatment”, Wat. Res., 34, pp. 945-951, 2000

[16] Daimon, H. K. Kang, N. Sato, and K. Fujie; "Development of marine waste recycling technologies using sub-and supercritical water", J. Chem. Eng. Japan, 34, pp.1091-1096, 2001

[17] Quitain, A.T., M. Faisal, K. Kang, H. Daimon, and K. Fujie; "Lowmolecular-weight carboxylic acids produced from hydrothermal treatment of organic wastes", J. Hazard. Mater., 93, pp. 209-220, 2002

[18] Quitain, A.T., N. Sato, H. Daimon and K. Fujie; "Production of valuable materials by hydrothermal treatment of shrimp shells", Ind. Eng. Chem. Res., 40, pp. 5885-5888, 2001

[19] Arai, K. and T. Adschiri; "Importance of phase equilibria for understanding supercritical fluid environments", Fluid Phase Equilibria., 158, pp. 673-684, 1999

[20] Park, Y., J.N. Hool, C.W. Curtis and C.B. Roberts; "Depolymerization of styrene-butadiene copolymer in near critical and supercritical water", Ind. Eng. Chem. Res., 37, pp. 1228-1234, 2001

[21] Akiya, N. and P.E. Savage; "Kinetics and mechanism of cyclohexanol dehydration in high - temperature water", Ind. Eng. Chem. Res., 40, pp. 1822-1831, 2001

[22] Mishra, V.S., V.V. Mahajani and J.B. Joshi; "Wet Air Oxidation", Ind. Eng. Chem. Res., 34, pp. 2-48, 1995

[23] Kao, C. B. Wang and W. Cheng; "Kinetic of hydrolytic depolymerization of melt poly (ethylene terepthalate)", Ind. Eng.Chem.Res., 37, pp.12281234,1998

[24] Tsuji, H., I. Fukui, H. Daimon and K. Fujie; "Poly (L-Lactide) XI. Lactide formation by thermal depolymerisation of poly (L-lactide) in a closed system”, Polym. Degrad. Stab., 81, pp. 501-509, 2003 